Revista Brasileira de Agricultura Irrigada v.11, nº.5, p. 1763 - 1771, 2017

ISSN 1982-7679 (On-line)

Fortaleza, CE, INOVAGRI - http://www.inovagri.org.br

DOI: $10.7127 /$ rbai.v11n500802

Protocolo 802.17 - 23/05/2017 Aprovado em 31/08/2017

\title{
CARACTERIZACIÓN DEL CRECIMIENTO DE UN CULTIVO DE MAÍZ REGADO EN UNA ZONA SEMIÁRIDA MEDIANTE EL EMPLEO DE IMÁGENES AÉREAS DE ALTA RESOLUCIÓN ${ }^{1}$
}

\author{
Fellype Rodrigo Barroso Costa르. José Fernando Ortega ${ }^{3}$, Krishna Ribeiro Gomes ${ }^{4}$, \\ Miguel Ángel Moreno ${ }^{5}$, Rocío Ballesteros ${ }^{6}$
}

\begin{abstract}
RESUMEN
Fue realizado el seguimiento fenológico, análisis de crecimiento y desarrollo del cultivo del maíz durante las campañas de riego de los años 2015 y 2016 en parcelas ubicadas en una finca comercial en Tarazona de La Mancha, Albacete, España. Se realizaron vuelos con un vehículo aéreo no tripulado (VANT) equipado con una cámara RGB, durante todo el ciclo del cultivo en ambos años. A partir de las imágenes capturadas en estos vuelos se obtuvieron ortoimágenes de alta resolución espacial, que fueron utilizadas para el cálculo del grado de cobertura verde (GCV) a partir del software de análisis de imágenes LAIC. El GCV presenta una baja cobertura vegetal al inicio de su ciclo, aumentando a medida en que se desarrolla el cultivo, hasta alcanzar su máximo valor, que en el año 2015 se dio al inicio de la etapa media del maíz (91,8\%), en cuanto que en el año 2016 los máximos valores de GCV fueron alcanzados al final de esta etapa (81\%). Al relacionar los valores de GCV con el índice de área foliar (IAF) en los dos años de estudio, se observa que el crecimiento de la cobertura vegetal está directamente relacionado con la evolución del área foliar del cultivo. Se concluye que el GCV es un parámetro importante en el análisis del desarrollo del cultivo del maíz, puesto que el estudio de las relaciones existentes entre el GCV y el IAF permitió analizar en detalle la arquitectura del cultivo y su evolución a lo largo del tiempo.
\end{abstract}

Palabras-clave: Grado de cobertura verde (GCV), índice de área foliar (IAF), vehículo aéreo no tripulado (VANT), Zea mays L

\footnotetext{
${ }^{1}$ Trabajo parte de la Tesis Doctoral del autor principal.

2 Ingeniero Agrónomo, Doctor, Centro Regional de Estudios del Agua (CREA), Universidad de Castilla-La Mancha, Ctra. de Las Peñas km. 3,4, 02071 Albacete, España. Email: fellype.rodrigo@hotmail.com.

${ }^{3}$ Profesor Titular, Centro Regional de Estudios del Agua (CREA), Universidad de Castilla-La Mancha, Ctra. de Las Peñas km. 3,4, 02071 Albacete, España. Email: jose.ortega@uclm.es.

${ }^{4}$ Ingeniero Agrónomo, Doctor, Centro Regional de Estudios del Agua (CREA), Universidad de Castilla-La Mancha, Ctra. de Las Peñas km. 3,4, 02071 Albacete, España. Email: krishnaribeiro@yahoo.com.br.

${ }^{5}$ Profesor Contratado Doctor, Centro Regional de Estudios del Agua (CREA), Universidad de Castilla-La Mancha, Ctra. de Las Peñas km. 3,4, 02071 Albacete, España. Email: miguelangel.moreno@uclm.es.

${ }^{6}$ Personal Investigador, Centro Regional de Estudios del Agua (CREA), Universidad de Castilla-La Mancha, Ctra. de Las Peñas km. 3,4, 02071 Albacete, España. Email: rocio.ballesteros@uclm.es.
} 


\title{
CARACTERIZAÇÃO DO CRESCIMENTO DA CULTURA DO MILHO IRRIGADO EM UMA ZONA SEMI-ÁRIDA MEDIANTE O EMPREGO DE IMAGENS AÉREAS DE ALTA RESOLUÇÃO ${ }^{1}$
}

\begin{abstract}
RESUMO
Foi realizado o seguimento fenológico, análise de crescimento e desenvolvimento da cultura do milho durante as campanhas de irrigação dos anos 2015 e 2016 em parcelas localizadas em uma propriedade comercial em Tarazona de La Mancha, Albacete, Espanha. Foram realizados voos com um veículo aéreo não tripulado (VANT) equipado com uma câmera RGB durante todo o ciclo da cultura em ambos anos. A partir das imagens capturadas nesses voos, foram obtidas ortoimagens de alta resolução espacial, que foram utilizadas para o cálculo do grau de cobertura verde (GCV) a partir do software de análises de imagens LAIC. O GCV apresenta uma baixa cobertura vegetal ao início do seu ciclo, aumentando à medida em que a cultura se desenvolve, até alcançar seu máximo valor, que no ano 2015 se deu ao início da etapa média do milho (91,8\%), enquanto que em 2016 os máximos valores de GCV foram alcançados ao final dessa etapa (81\%). Ao relacionar os valores de GCV com o índice de área foliar (IAF) nos dois anos de estudo, se observa que o crescimento da cobertura vegetal está diretamente relacionado com a evolução da área foliar da cultura. Se conclui que o GCV é um parâmetro importante na análise do desenvolvimento da cultura do milho, já que o estudo das relações existentes entre o GCV e o IAF permitiu analisar em detalhe a arquitetura da cultura e sua evolução ao largo do tempo.
\end{abstract}

Palavras-chave: Grau de cobertura verde (GCV), índice de área foliar (IAF), veículo aéreo não tripulado (VANT), Zea mays L..

\section{INTRODUCCIÓN}

El maíz (Zea mays L.) es un cultivo herbáceo, de la familia Gramineae o Poaceae (SAAVEDRA, 2014). Es el segundo cultivo más cultivado en el mundo, con una producción que sobrepasa los 1.000 millones de toneladas. Tiene como mayores productores Estados Unidos, China y Brasil, en este orden, según la Organización de las Naciones Unidas para la Alimentación y la Agricultura (FAO) (2014).

En regiones áridas y semiáridas, como Castilla-La Mancha, el regadío es una actividad muy importante, debido a la escasez de agua característica en estas zonas. La caracterización del crecimiento y desarrollo del cultivo es una herramienta fundamental para la toma de decisiones en agricultura (VIATOR et al., 2005). El concepto de grados días acumulados (GDA) involucra tanto la combinación adecuada de temperatura y tiempo cronológico para cada cultivo, como la definición de las temperaturas umbrales mínimas $\left(\mathrm{Tu}_{\text {mín}}\right)$ y máximas $\left(\mathrm{Tu}_{\operatorname{máx}}\right)$ que, excedidas, provocan que el crecimiento sea nulo o insignificante.

La mayoría de los modelos de cultivos, como por ejemplo AQUACROP (RAES et al., 2011) utilizan el índice de área foliar (IAF) como principal parámetro para modelar el crecimiento y desarrollo de los cultivos. En la actualidad, se han desarrollado diferentes técnicas que permiten la determinación del IAF mediante índices y parámetros de vegetación obtenidos gracias a imágenes de muy alta resolución, como el grado de cobertura verde (GCV). El GCV, que se define como la fracción de suelo cubierto por la vegetación verde, está relacionado con el suelo y su protección contra la erosión, fenómenos atmosféricos y de transpiración, clima, estrés del cultivo y manejo de la cubierta vegetal.

La utilización de los vehículos aéreos no tripulados (VANTs) en agricultura ofrece nuevas posibilidades para la obtención de imágenes aéreas de muy alta resolución. Estas imágenes aéreas pueden ser utilizadas para la 
obtención de parámetros importantes en la modelación del crecimiento de los cultivos, como es el caso del GCV, a su vez relacionado con diferentes índices del crecimiento, desarrollo y producción de los cultivos (BALLESTEROS et al., 2014b; CÓRCOLES et al., 2013).

Así, se planteó como objetivo de este trabajo caracterizar el crecimiento y desarrollo del maíz, mediante el empleo de imágenes de alta resolución para la descripción de la relación del GCV con el IAF.

\section{MATERIALES Y MÉTODOS}

Durante los años 2015 y 2016 se realizó el seguimiento fenológico y análisis del crecimiento y desarrollo del cultivo de maíz en dos parcelas comerciales de una finca ubicada en Tarazona de la Mancha (Albacete) en la U.H. 08.29. (Mancha Oriental), España. En estas parcelas se practicaba el no laboreo, que consiste en trabajar el mínimo posible el suelo. Además, se utilizaron variedades de maíz del ciclo 700, en parcelas con sistema de riego pívot central, con un área de 42 ha en la parcela del año 2015 y 37 ha en la del año 2016. En relación al aporte total de agua, se aplicó un total de 8.816,5 $\mathrm{m}^{3} \mathrm{ha}^{-1}$ en la parcela del año 2015, y 8.067,1 $\mathrm{m}^{3} \mathrm{ha}^{-1}$ en el año 2016. Se utilizó como referencia para la determinación del estadio fenológico del cultivo la escala BBCH (HACK et al., 1992), con la cual se registraron los cambios fenológicos del cultivo de forma semanal, lo que permitió una adecuada planificación de los muestreos en campo. Al inicio del ciclo del maíz se observaron los cambios relativos a la cantidad de hojas desplegadas del cultivo. Posteriormente, con el alargamiento de la caña, se cuantificaron los nudos visibles. Con la aparición del órgano floral, es necesario cuantificar el tamaño del penacho, además de qué porción de éste está visible. Luego, con el inicio de la floración, los parámetros a tener en cuenta son el estambre y el estigma, que empiezan a emerger. Con el estambre emergido, se desprende el polen. Al final de la floración, empieza la formación del fruto. En este estadio, es necesario monitorizar la composición del grano y su contenido. Tras esto, empieza la maduración de la mazorca. Cuando el cultivo alcanza la madurez completa, empieza el proceso de senescencia, coincidiendo con el secado del grano.

En los dos años de este estudio, antes del inicio de la campaña de riego, se hizo un vuelo con un VANT equipado con una cámara digital automática RGB para una primera caracterización de la parcela, con suelo desnudo. Con la utilización de las imágenes obtenidas en este vuelo previo y la ayuda del técnico de la explotación, se identificaron las distintas zonas existentes en las parcelas (4 zonas de muestreo en 2015 y 3 en 2016). Las parcelas estudiadas presentaban un suelo con textura media y poca profundidad.

En la Tabla 1 están presentados los valores medios de temperatura máxima (Tmáx) y (Tmín) mínima para los meses de estudio para el maíz en los años 2015 y 2016. Durante el periodo de estudio, la ETo total fue de, respectivamente, 859,5 mm y 847,2 mm y la precipitación total fue de 146,1 mm y 208,7 mm en los años 2015 y 2016.

Tabla 1. Valores medios de temperatura máxima (Tmáx) y mínima (Tmín) durante los meses de estudio en el maíz grano en los años 2015 y 2016.

\begin{tabular}{cccccccc}
\hline \multicolumn{7}{c}{ Año 2015} \\
\hline Mes & Abril & Mayo & Junio & Julio & Agosto & Septiembre & Octubre \\
\hline Tmáx $\left({ }^{\circ} \mathrm{C}\right)$ & 18,8 & 26,5 & 29,5 & 36,2 & 31,9 & 25,3 & 23,0 \\
Tmín $\left({ }^{\circ} \mathrm{C}\right)$ & 6,4 & 10,4 & 14,1 & 18,8 & 17,7 & 12,4 & 11,0 \\
\hline \multicolumn{7}{c}{ Año 2016} \\
\hline Tmáx $\left({ }^{\circ} \mathrm{C}\right)$ & 17,5 & 21,6 & 30,0 & 33,6 & 32,5 & 28,8 & 23,1 \\
Tmín $\left({ }^{\circ} \mathrm{C}\right)$ & 5,5 & 8,5 & 13,3 & 17,1 & 16,6 & 13,7 & 10,8 \\
\hline
\end{tabular}


Fuente: Datos meteorológicos obtenidos de la estación de Tarazona de la Mancha (X: 593160; Y: 4345720), a través del Servicio de Información Agroclimática para el Regadío (SIAR) (www.siar.es). Consultado el 11/09/2015.

Con el cálculo de los grados días acumulados (GDA), es posible determinar la duración de las etapas de desarrollo del cultivo, permitiendo así una mejor planificación de la programación de riegos o de cualquier otro aspecto en el manejo de los cultivos. Según
Ballesteros et al. (2014a), el método del seno doble es el más adecuado para el cálculo de los GDA en el cultivo del maíz. Las temperaturas umbrales para el cálculo de los GDA por esta metodología están presentadas en la Tabla 2, según los mismos autores.

Tabla 2. Temperaturas umbrales mínima $\left(\mathrm{Tu}_{\operatorname{mín}}\right)$ y máxima $\left(T u_{\text {máx }}\right)$ para el cultivo del maíz en todas sus etapas de desarrollo fenológico.

\begin{tabular}{ccccc}
\hline & Etapa I & Etapa II & Etapa III & Etapa IV \\
\hline $\mathrm{Tu}_{\text {mín }}\left({ }^{\circ} \mathrm{C}\right)$ & 6 & 7 & 12 & 6 \\
$\mathrm{Tu}_{\text {máx }}\left({ }^{\circ} \mathrm{C}\right)$ & 26 & 31 & 38 & 40 \\
\hline
\end{tabular}

Fuente: (Ballesteros et al., 2014).

Durante los dos años de estudio se realizaron muestreos de campo coincidiendo con los momentos más relevantes del ciclo de crecimiento y desarrollo y considerando el seguimiento realizado en campo, en la cual se recogían 6 plantas en cada una de las zonas de muestreo de las parcelas en cada día de muestreo. En laboratorio, se determinó el IAF para cada una de las zonas de muestreo, al relacionar el promedio del área foliar (AF) de cada zona con la densidad de plantas para cada una de estas zonas.

Además del muestreo de plantas, se realizaron vuelos del VANT en cada uno de los días de muestreo de campo, en que se capturaron imágenes aéreas de muy alta resolución. Para dichos vuelos, en la campaña del año 2015, se utilizó un VANT tipo cuadracóptero, modelo md4-200 (Microdrones, Inc., Kreuztal, Alemania), con despegue y aterrizaje vertical (FIGURA 1). Este modelo de VANT se caracteriza por presentar cuatro rotores, lo que permite el despegue y aterrizaje de forma vertical, eliminando la necesidad de un amplio espacio para dichas maniobras. En el año 2016 se utilizó en VANT modelo md4-1000 (Microdrones, Inc., Kreuztal, Alemania), también de despegue y aterrizaje verticales (FIGURA 2).

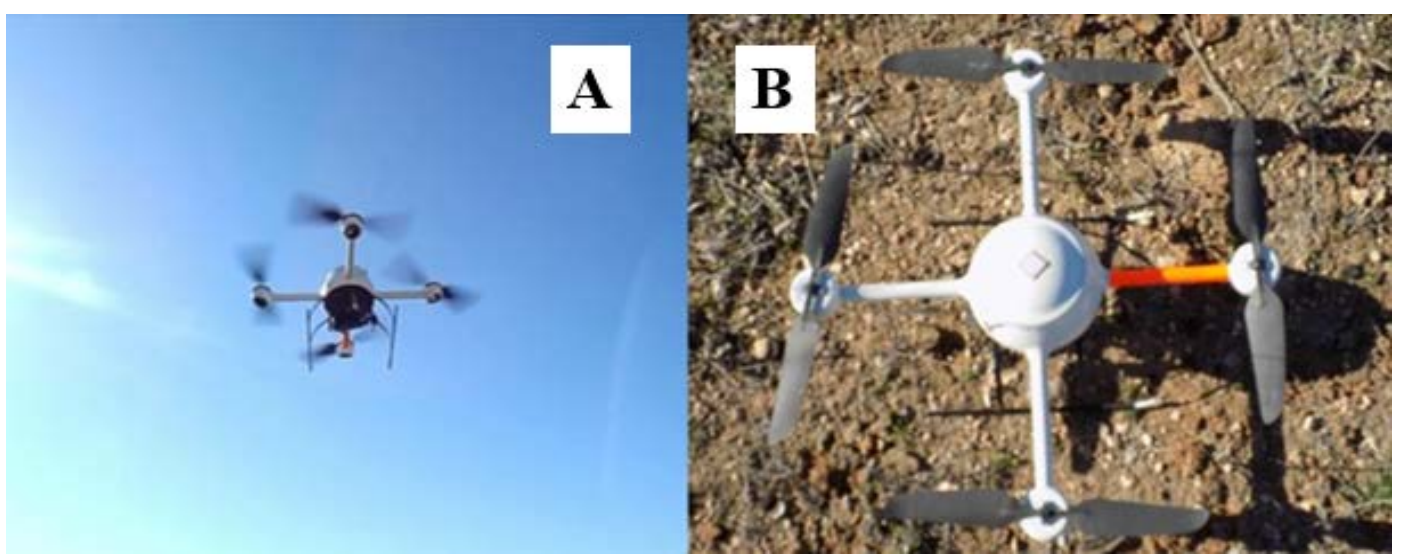

Figura 1. Vehículo aéreo no tripulado (VANT) modelo md4-200, con cámara digital automática RGB Canon Ixus HS115 durante el vuelo (1A) y antes del despegue (1B), utilizados en este estudio. 


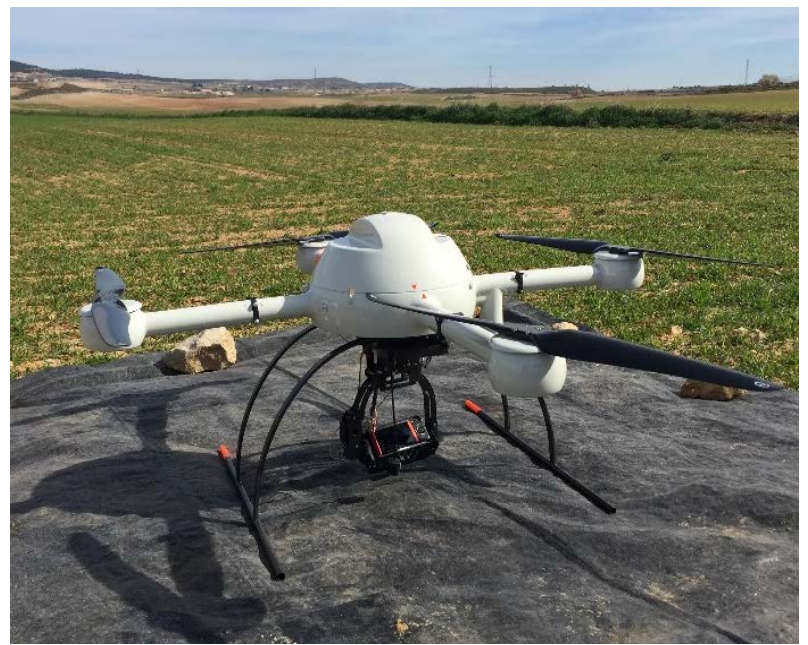

Figura 2. Vehículo aéreo no tripulado (VANT) modelo md4-1000, con cámara digital automática RGB Sony ILCE-5100 utilizados en este estudio.

Para la obtención de las imágenes aéreas fueron utilizadas cámaras digitales automáticas RGB. En el año 2015 se utilizó la cámara digital automática modelo Ixus HS115, (Canon Inc., Tokio, Japón), de 12 Mpx de resolución y con un tamaño de pixel (GSD) de $4 \mathrm{~cm}$. En el año 2016 se utilizó la cámara digital automática modelo ILCE-5100 (Sony Corporation, Tokio, Japón), con una resolución de 24 Mpx y un GSD de 2,5 cm.

Tras la captura de las imágenes aéreas en campo, estas fueron sometidas a un proceso fotogramétrico, utilizando para ello el software PhotoScan (Agisoft LCC, St. Petersburg, Rusia). A partir de este proceso, fue posible la obtención de productos geomáticos que permiten la extracción de información agronómica útil, como es el caso de la ortoimagen, del modelo digital del terreno (MDT) y la nube densa de puntos (3D).

A partir de la ortoimagen, fue posible calcular el GCV en cada uno de los puntos de muestreo en el cultivo de maíz durante las campañas de riego de los años 2015 y 2016. Para este cálculo, se utilizó el software Leaf Area Index Calculation (LAIC) (CÓRCOLES et al., 2013), desarrollado en el entorno MATLAB (Natick, MA, EE.UU). El software permite seleccionar una pequeña parte de una imagen RBG y la convierte en una imagen del tipo L*a*b. Posteriormente, se hace un análisis clúster de esta imagen, con la función k-means de MATLAB. Este análisis identifica los distintos grupos de colores presentes en la imagen y los agrupa en cuantos grupos el usuario lo indique al software. Estos distintos grupos de colores se relacionan con los diversos elementos presentes en la ortoimagen, como por ejemplo, hojas del cultivo, malas hierbas, suelo, piedras, sombras del cultivo, entre otros. Después del análisis clúster, el usuario separa manualmente los grupos correspondientes a la cobertura verde del cultivo, haciendo que el software calcule el porcentaje correspondiente al cultivo en relación al área total de la imagen seleccionada. Posteriormente, el LAIC genera dos imágenes, una con la selección de los grupos correspondientes a la cobertura verde del cultivo y otra con los grupos relacionados con los demás elementos contenidos en la imagen original. Una nueva actualización del software permite que el mismo genere las dos imágenes georreferenciadas, permitiendo contrastarlas con la imagen original en programas específicos.

El IAF y el GCV fueron analizados en función del tiempo térmico, además de haber sido analizados entre ellos. Para la relación IAF-GCV se probaron los modelos lineal y polinomial de segundo grado (BALLESTEROS, 2014).

Para la decisión sobre la selección de qué modelo adoptar para esta relación, se calculó el coeficiente de determinación ajustado $\left(\mathrm{R}^{2}\right.$ ajustado) y la raíz del error cuadrático medio 
(RMSE). La decisión se tomaba en base al modelo que presentase el $\mathrm{R}^{2}$ ajustado más alto y el RMSE más bajo. Debido a la similitud de comportamiento de los modelos en algunas situaciones, el RMSE tuvo gran importancia en esta selección, ya que, con valores de $\mathrm{R}^{2}$ ajustado muy similares, los errores más bajos caracterizaban el mejor ajuste del modelo.

\section{RESULTADOS Y DISCUSIÓN}
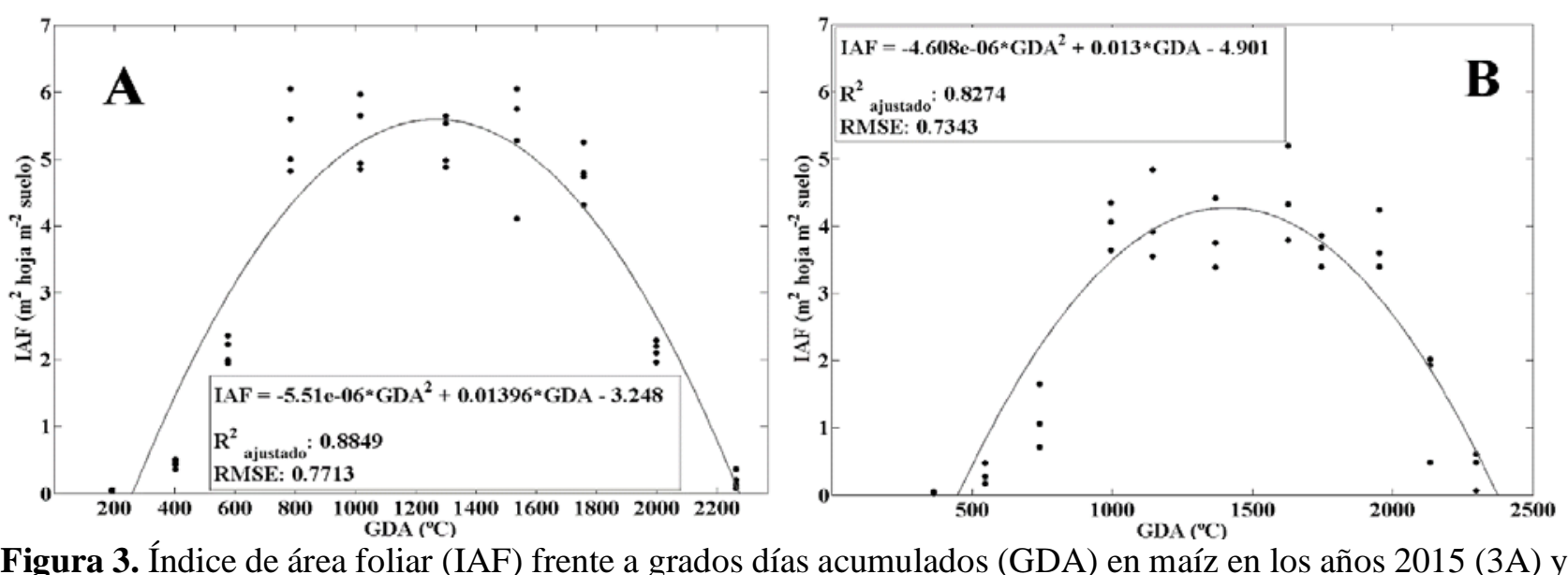

Figura 3. Índice de área foliar (IAF) frente a grados días acumulados (GDA) en maíz en los años 2015 (3A) y 2016 (1B).

Fuente: Elaboración propia.

A partir de la Figura 3A se observa que, en el año 2015, el IAF alcanzó su valor máximo en el final de la etapa II $\left(6,05 \mathrm{~m}^{2}\right.$ hoja $\mathrm{m}^{-2}$ suelo), manteniendo valores similares hasta el final de la etapa III (entorno a los $5 \mathrm{~m}^{2}$ hoja $\mathrm{m}^{-2}$ suelo), cuando empieza a decaer, debido a la senescencia. En la Figura 3B se observa que, en 2016, el cultivo presentó un comportamiento similar al año anterior, en que el maíz grano tiene valores muy bajos de IAF al inicio de su ciclo, alcanzando $5,12 \mathrm{~m}^{2}$ hoja $\mathrm{m}^{-2}$ suelo al final de la etapa II, manteniendo estos valores constantes hasta el final de la etapa III (cerca de $4 \mathrm{~m}^{2}$ hoja $\mathrm{m}^{-2}$ suelo), cuando empieza a disminuir considerablemente al final de su ciclo, debido a la senescencia. Los valores de IAF más bajos en el año 2016 pueden ser explicados por los problemas de nascencia ocurridos al inicio de la campaña en este año.

Otros estudios que encontraron valores de IAF similares a los de este estudio fueron
En la Figura 3A se presentan los resultados de IAF frente a GDA para el maíz en el año 2015. El modelo que mejor se ajusta a ese parámetro es el polinomial de segundo grado, con $\mathrm{R}_{\text {ajustado }}=0,88$ y RMSE $=0,78 \mathrm{~m}^{2}$ hoja $\mathrm{m}^{-2}$ suelo. En la Figura 3B se presentan los valores de IAF frente a GDA en el maíz para el año 2016. Para este año el modelo que mejor se ajusta a este parámetro es el polinomial de segundo grado, con $\mathrm{R}_{\text {ajustado }}=0,83$ y RMSE= $0,73 \mathrm{~m}^{2}$ hoja $\mathrm{m}^{-2}$ suelo, así como en el año anterior. los de López (2004), que estudiando el maíz en La Mancha Oriental, encontró valores máximos de IAF en torno a $5,5 \mathrm{~m}^{2}$ hoja $\mathrm{m}^{-2}$ suelo, decreciendo estos valores al final del ciclo fenológico del maíz. Además, el comportamiento del IAF en relación al tiempo es el mismo del presente trabajo (polinomial de segundo grado), con valores de IAF bajos al inicio del ciclo, alcanzando su máximo valor en la etapa media $y$ presentando una disminución de los valores al final del ciclo.

El GCV frente a los GDA, en los dos años (2015 y 2016), está presentado en la Figura 4. Para ambos años, el GCV tuvo un comportamiento ajustado a un modelo polinomial de segundo grado, con $\mathrm{R}^{2}$ ajustado= 0,89 y RMSE $=8,5 \%$ en el año 2015 (FIGURA 4A) y un $R^{2}{ }_{\text {ajustado }}=0,79$ y RMSE $=9,2 \%$ en el año 2016 (FIGURA 4B).

Se observa que el GCV presenta comportamiento semejante al del IAF en los dos años, ya que presenta valores bajos en el 
inicio del ciclo, alcanza su máximo valor en el inicio de la etapa III, llegando a 91,8\% de cobertura verde en una de las zonas en el año 2015 (783 GDA) y 81\% en el año 2016 (1.628 GDA). Los altos valores de GCV se mantienen hasta el final de la etapa III y empiezan a decrecer debido a la senescencia.
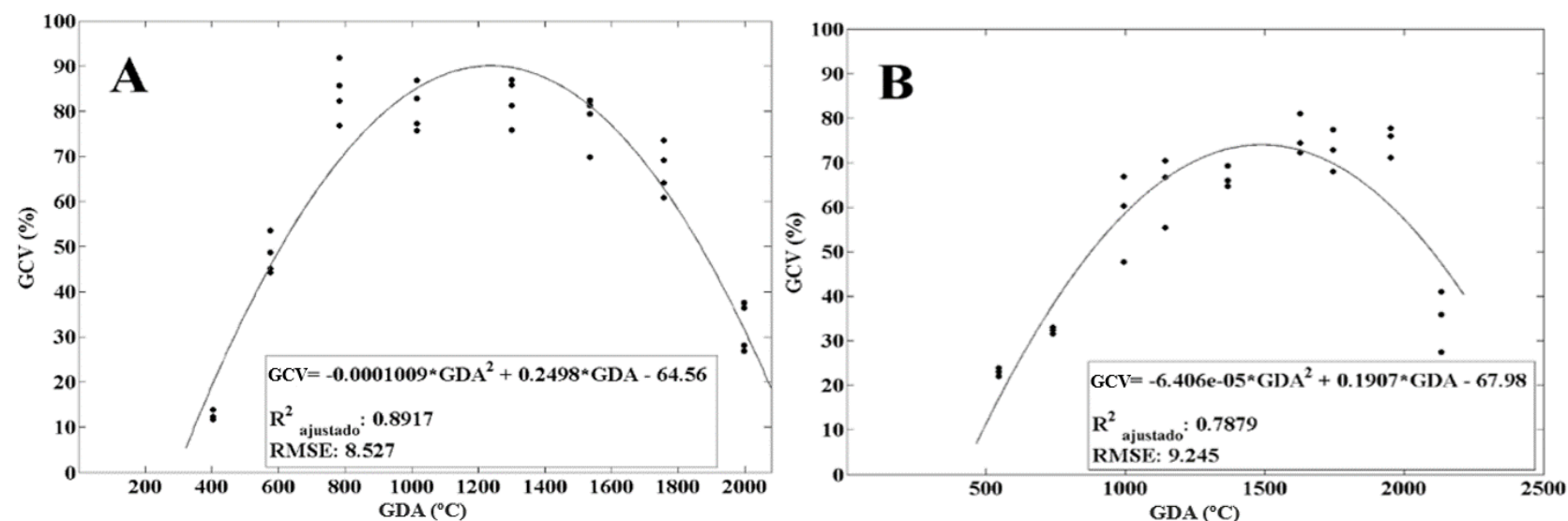

Figura 4. Grado de cobertura verde (GCV) frente a los grados días acumulados (GDA) en maíz en los años 2015 (4A) y 2016 (4B).

Fuente: Elaboración propia.

En el año 2015 (FIGURA 4A), la cobertura verde presenta un comportamiento similar al del año 2016 (FIGURA 4B), pero, debido a una densidad de plantas más alta, el GCV presenta valores más altos en este año que en 2016. Así mismo, se aprecia que los cambios en la cobertura verde ocurren en las mismas etapas de desarrollo del cultivo en los dos años.

Algunos autores, como Ballesteros et al. (2014b), estudiando el cultivo del maíz en La Mancha Oriental, describieron un comportamiento de la cobertura verde similar al encontrado en los dos años de este estudio, pero sus valores máximos de GCV llegaron a los $80 \%$ en la etapa media de desarrollo del cultivo, habiendo una disminución en la etapa final de su desarrollo, debido a la senescencia, en cuanto que en el presente estudio se consiguió una cobertura verde máxima de 91,8\% en el año 2015 y 81\% en el año 2016.

En la Figura 5 se presentan los resultados de la relación IAF-GCV en los años 2015 (FIGURA 5A) y 2016 (FIGURA 5B), con el modelo polinomial de segundo grado siendo el que mejor representa esta relación, con $\mathrm{R}_{\text {ajustado }}^{2}=0,94$ y 0,91 y RMSE $=0,4$ y $0,4 \mathrm{~m}^{2}$ hoja $\mathrm{m}^{-2}$ suelo para los años 2015 y 2016, respectivamente.

En la Figura 5A se observa que en el año 2015 el crecimiento del GCV está directamente relacionado con el IAF: cuando el cultivo alcanza su máximo IAF, éste alcanza también su máxima cobertura verde. En el año 2016 (FIGURA 5B) el IAF aumenta hasta llegar al 70\% de la cobertura verde. A partir de ahí, los valores tienden a estabilizarse, presentando poca variación de los valores de IAF en relación al aumento del GCV. 

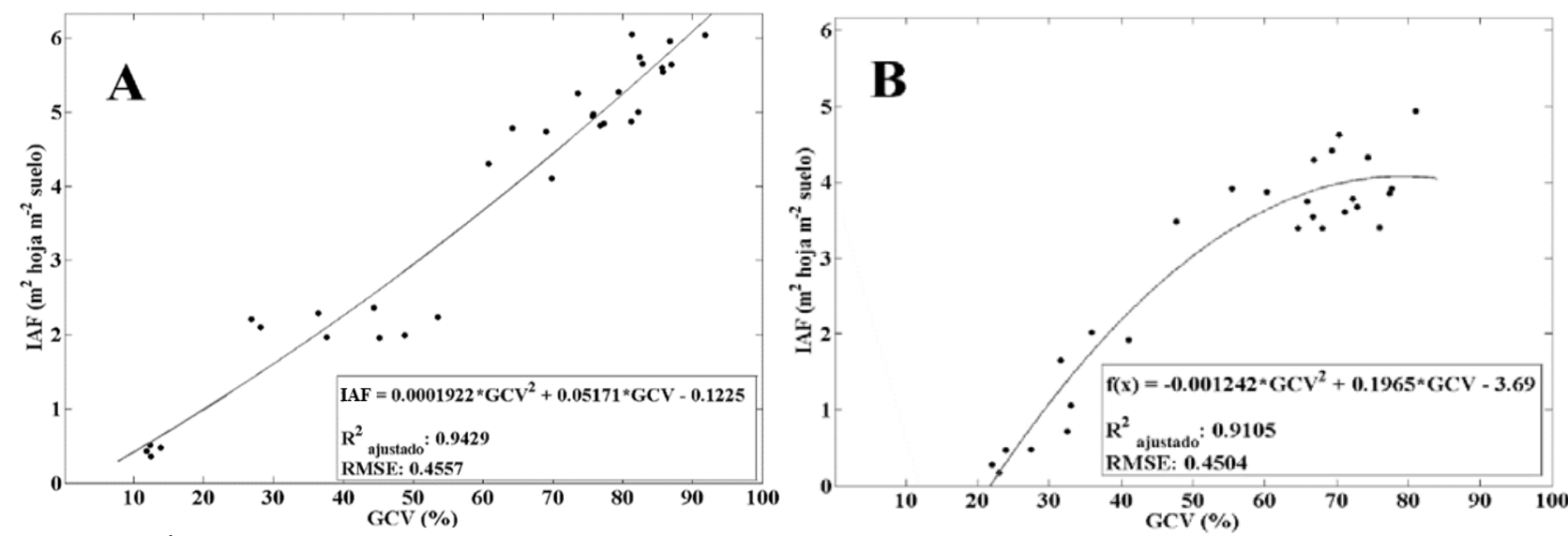

Figura 5. Índice de área foliar (IAF) frente al grado de cobertura verde (GCV) en maíz grano en los años 2015 (5A) y 2016 (5B).

Fuente: Elaboración propia.

Autores como Ballesteros et al. (2014), estudiando el maíz grano en la Mancha Oriental, encontraron como resultados de la relación IAF-GCV un comportamiento polinomial de segundo grado, lo mismo que en este estudio. Con bajos valores de IAF, el modelo indica una baja cobertura vegetal. A la medida en que aumenta el IAF, se incrementan también los valores del GCV, hasta que el IAF alcanza su máximo valor, manteniéndose estable, en cuanto que la cobertura vegetal sigue incrementando sus valores.

\section{CONCLUSIONES}

Se concluye que el GCV es un parámetro importante en el análisis del desarrollo del cultivo del maíz, puesto que el estudio de las relaciones existentes entre el GCV y el IAF permitió analizar en detalle la arquitectura del cultivo y su evolución a lo largo del tiempo. Los modelos polinomiales de segundo orden y los lineales resultaron los más adecuados para representar las relaciones en el maíz.

\section{AGRADECIMIENTOS}

A la Universidad de Castilla-La Mancha, al Centro Regional de Estudios del Agua (CREA) y al Proyecto IBrasil Erasmus Mundus por el apoyo financiero y logístico necesarios en la realización de los trabajos.

\section{REFERENCIAS BIBLIOGRÁFICAS}

BALLESTEROS, R. Predicción de evapotranspiración de referencia y empleo de modelos de tiempo térmico junto a información geomática en la caracterización de cultivos para la gestión del regadío en la Mancha Oriental. 2014. 174 p. Tesis Doctoral. English. Universidad de Castilla-La Mancha, Albacete.

BALLESTEROS, R., ORTEGA, J. F., HERNÁNDEZ, D., \& MORENO, M. A. Applications of georeferenced high-resolution images obtained with unmanned aerial vehicles. Part I: Description of image acquisition and processing. Precision Agriculture, v. 15, n. 6, p. 579-592, 2014a. http://doi.org/10.1007/s11119-014-9355-8

BALLESTEROS, R., ORTEGA, J. F., HERNÁNDEZ, D., \& MORENO, M. A. Applications of georeferenced high-resolution images obtained with unmanned aerial vehicles. Part II: application to maize and onion crops of a semi-arid region in Spain. Precision Agriculture, v. 15, n. 6, p. 593-614, 2014b. http://doi.org/10.1007/s11119-0149357-6

CÓRCOLES, J. I., ORTEGA, J. F., HERNÁNDEZ, D., \& MORENO, M. A. Estimation of leaf area index in onion (Allium сера L.) using an unmanned aerial vehicle. Biosystems Engineering, v. 115, n.1, p. 31- 
42,

2013.

http://doi.org/10.1016/j.biosystemseng.2013.0 2.002

FAO. FAO Stat, 2014. Retrieved from www.fao.org/faostat/

HACK, H., BLEIHOLDER, H., BUHR, R., MEIER, U., SCHNOCK-FRICKE, E., WEBER, E., \& WITZENBERGER, A. Einheitliche codierung der phänologischen entwicklungsstadien mono-und dikotyler pflanzen-erweiterte BBCH-Skala, Allgemein. Limburgerhof: BASF Aktiengesellschaft, 1992. 123 p.

LÓPEZ, H. Modelización de la respuesta agronómica del cultivo del maíz (Zea mayz L.) a la dosis de nitrógeno. 2004. 204 p. Tesis
Doctoral. Universidad de Castilla-La Mancha, Albacete.

RAES, D., STEDUTO, P., HSIAO, T. C., \& FERERES, E. Chapter 1. FAO cropwater productivity model to simulate yield response to water AquaCrop. Reference Manual of AQUACROP, (January), 56. 2011.

SAAVEDRA, G. El cultivo del maíz choclero y dulce. Santiago, Chile. 2014.

VIATOR, R. P., JOHNSON, R., \& RICHARD JR., E. P. Challenges of post-harvest residue management in the Louisiana sugarcane industry. Proceedings - International Society of SugarcaneTechnologists, v. 25, p. 238244, 2005. 